\title{
In memoriam Aldo Calanca
}

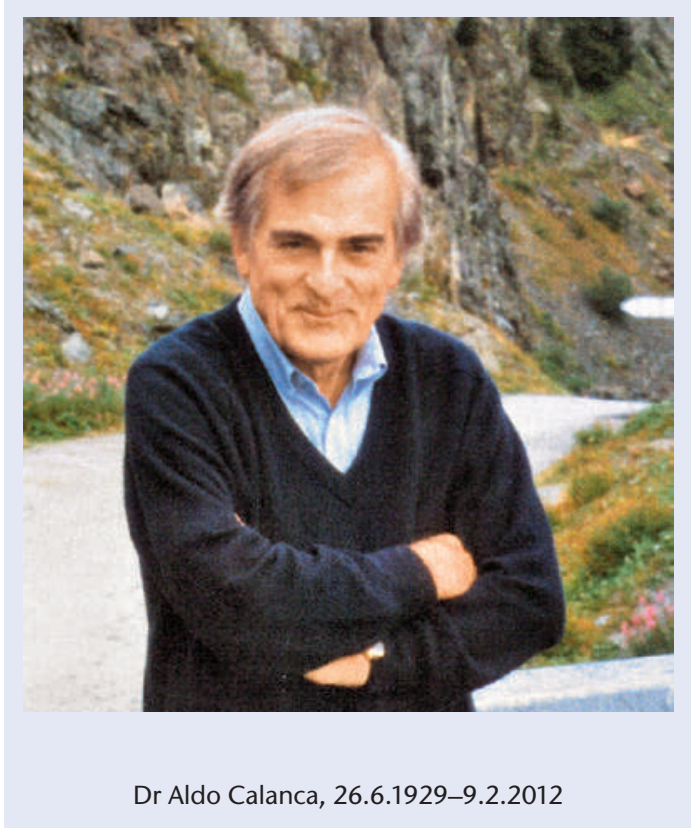

C’est un médecin unanimement apprécié de ses patients comme de ses confrères qui nous a quittés le 9 février, dans sa $83^{e}$ année. Le Dr Aldo Calanca a été médecin-cadre à l'Hôpital psychiatrique universitaire vaudois de Cery durant plus de vingt ans.

Tout au long de sa carrière il a fait preuve d'originalité, au meilleur sens du terme. Ainsi, il s'est beaucoup engagé dès les années 1970 dans la problématique lourde de la toxicomanie, aux drogues illégales comme à l'alcool. Ceci alors que rares étaient, parmi ses confrères psychiatres, ceux qui s'attachaient aux addictions, dont l'importance en termes de santé publique était pourtant manifeste. Dans un autre domaine lui aussi vu comme difficile, il est devenu une référence pour l'évaluation des situations transgenre.

En tant que médecin cantonal, j'ai eu le privilège de collaborer étroitement avec lui, en rapport avec les prises en charge à l'aide de méthadone. Grâce au charisme et au style confraternel du Dr Calanca a été mis sur pied un programme de perfectionnement destiné aux médecins suivant des toxicomanes à leur cabinet. Programme qui a représenté un moyen substantiel d'échanges et de soutien professionnel, pour des dizaines de praticiens acceptant de s'engager dans le suivi, qui a ses frustrations, de personnes abusant de substances.

Dans ses fonctions hospitalières, Aldo Calanca participait à l'enseignement; beaucoup s'en souviennent comme l'un des meilleurs qu'ils aient eus. Il était l'auteur principal d'un Vademecum de thérapeutique psychiatrique (chez Médecine et Hygiène) dont, belle preuve de son apport, la $10^{\mathrm{e}}$ édition a été publiée quelques semaines avant qu'il ne s'en aille sans crier gare.

Dans ses nombreux sujets d'intérêt extraprofessionnels, il s'est là aussi montré atypique, surprenant parfois, comme l'a rappelé sa fille Manuela lors du service funèbre. Amateur de musique, il était un clarinettiste/saxophoniste de jazz passionné. Beaucoup de raisons de garder de lui un souvenir ému. Ciao dottore!

Dr Jean Martin, ancien médecin cantonal vaudois 